\title{
Megamerinidae (Diptera), a new family for Portugal
}

Rui Andrade

\begin{abstract}
Megamerinidae (Diptera), a new family for Portugal. - Čas. Slez. Muz. Opava (A), 60: 179-180, 2011.

Abstract: Megamerina dolium (Fabricius, 1805), a usually infrequently collected medium-sized fly occurring in forested areas, is the sole known representative of Megamerinidae in Europe, currently recorded for twenty-one countries. In this article the species is reported for the first time in Portugal, and consequently the first time the family is recorded for this country as well. This record represents the westernmost limit of the distribution of this species.

Key words: Diptera, Megamerinidae, Megamerina dolium, new record, Portugal, distribution
\end{abstract}

\section{Introduction}

Megamerinidae is a small family of acalyptrate Diptera, represented in Europe by only one species, Megamerina dolium (Fabricius, 1805). In this article the species Megamerina dolium and the family Megamerinidae are recorded for the first time in Portugal, this being the westernmost known record of this species. In the Iberian Peninsula, it was only recorded from the Pyrenees (Carles-Tolrá 1995), but it is widespread in the Palaearctic, having been recorded for the following countries (Whitmore 2004): Andorra, Austria, Belgium, Czech Republic, Denmark, Finland, France, Germany, Great Britain, Hungary, Italy, the Netherlands, Norway, Poland, Romania, Russia (South and Centre European territories, Ossetia, Altay, Tuva, Buriatia, Amur and Primorye), Slovakia, Sweden, Switzerland and Ukraine. Since then, it has been recorded also from Greece where over 50 specimens were collected in one site over a period of a year (flight period: early May to mid-August) (Ramel 2009). Despite its extensive distribution, it is usually an infrequently collected species.

M. dolium is a medium-sized $(6.0-8.5 \mathrm{~mm})$ species, with elongated and glossy dark body, unmarked wings and reddish femora. The hind femora are swollen and provided with two rows of spines on the ventral surface (Hennig 1941). The adults live mostly in forested areas and larvae can be found under bark of dead or dying deciduous trees, where they are apparently necrophagous or live as predators of other insect larvae (Nartshuk 1984).

Megamerina dolium (Fabricius, 1805)

Portugal: Porto, Vila Nova de Gaia, Avintes, Parque Biológico de Gaia, 4106'00.20"N, 8³3'33.10"W, cca. 50 m. Collected with a vial while moving on a leaf of Rubus sp. in a shaded area, 23.v.2011, 1 , R. Andrade leg. The specimen is preserved in $70 \%$ ethanol and deposited in the author's private collection.

The site where the specimen was found is situated in the valley of the river Febros, a tributary of the river Douro, and is included within the area of Parque Biológico de Gaia ("Gaia Biological Park"), an urban park and an environmental education centre created in 1983 that occupies an area of 35 hectares. An important portion of the park is forested, with the following predominant tree and herb species: Quercus robur, Alnus glutinosa, Salix spp., Betula sp., Castanea sativa, Sambucus nigra, Urtica sp. and Rubus sp. Given the biology of the species, it is worth keeping decomposing tree and dying trees wherever they lie, so that the species can complete its life cycle and survive in the area successfully. Of course, this would significantly aid also the survival of many more saproxylic insects. 
Acknowledgements: The author wishes to thank Águas e Parque Biológico de Gaia, EEM and Ecoinside Lda., for supporting the work during which the specimen was collected, Dr. D. Whitmore for providing a reference, Dr. Jindřich Roháček for suggestions while writing the manuscript and Dr. Martin Ebejer and Dr. Andrzej Woźnica for reviewing the article.

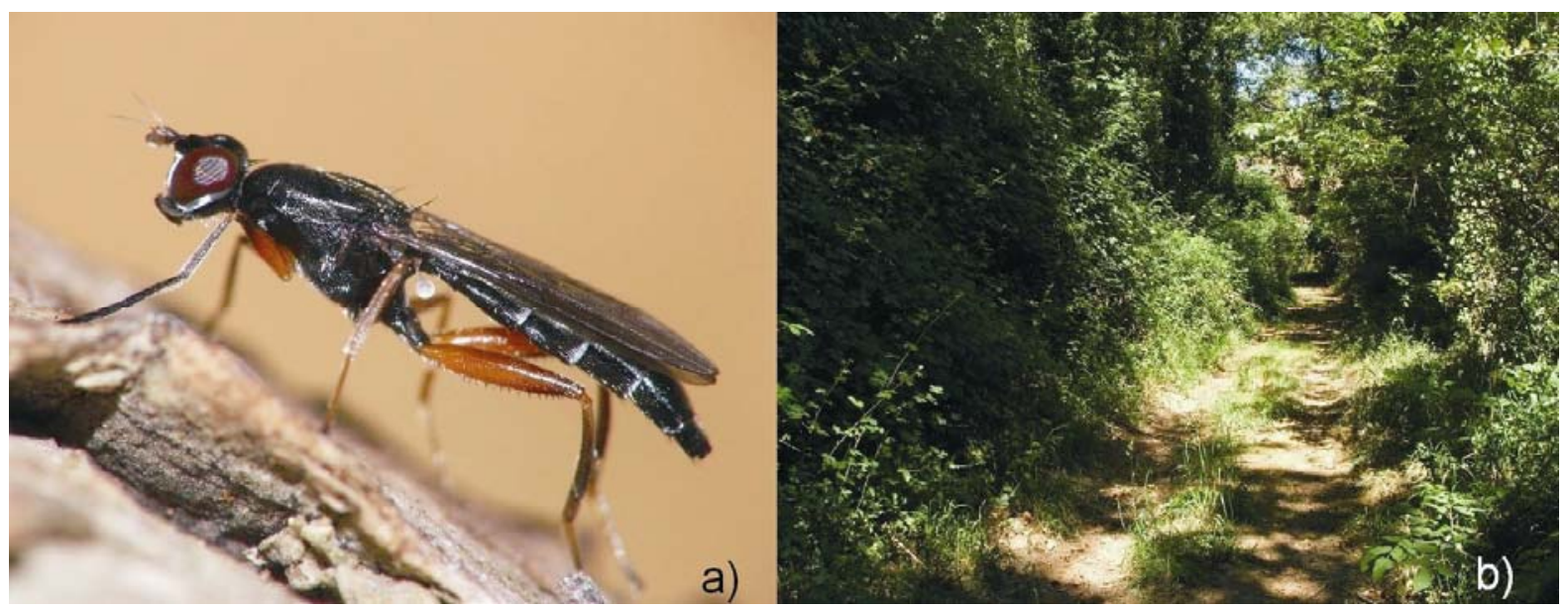

Fig. 1: Megamerina dolium and its habitat: a) the female collected in Portugal; b) Habitat where this specimen was collected.

\section{Reference}

Carles-Tolrá M. (1995): Megamerinidae: nueva familia de dípteros acalípteros para la Península Ibérica. Bol. Asoc. Esp. Entomol. 19(3-4): 205-206.

Hennig W. (1941): 39b. Megamerinidae. In Lindner E. (ed.): Die Fliegen der Paläarktischen Region. Vol. 5, Pt. 1. E. Schweitzerbart'sche Verlagsbuchhandlung, Stuttgart, 4 pp.

Nartshuk E. P. (1984): Family Megamerinidae, pp. 25-26. In Soós Á. \& Papp L. (eds.): Catalogue of Palaearctic Diptera, Vol. 9, Micropezidae-Agromyzidae. Elsevier Scientific Publications, Amsterdam \& Akadémiai Kiadó, Budapest, 460 pp.

Ramel, G. (2009): Some new records of saproxylic brachycera for Wetland kerkini, northern Greece (Diptera: Megamerinidae, Strongylophthalmyiidae, Xylomyidae and Xylophagidae). Dipterists Digest 16 (2): 95-99.

Whitmore D. (2004): Notes on two species of acalyptrate flies (Diptera: Megamerinidae, Ulidiidae). - Boll. Assoc. Romana Entomol. 59(1-4): 103-109.

Author's address: Rui Andrade, Rua Dr. Abel Varzim 16 2-D, 4750-253 Barcelos, Portugal, e-mail: ruiamandrade@yahoo.com 